\title{
Attitudes and perceptions of Dutch veterinarians on their role in the reduction of antimicrobial use in farm animals
}

\author{
David C. Speksnijder ${ }^{\mathrm{a}, \mathrm{b}, *}$, Debbie A.C. Jaarsma ${ }^{\mathrm{c}}$, Theo J.M. Verheij ${ }^{\mathrm{d}}$, Jaap A. Wagenaar ${ }^{\mathrm{a}, \mathrm{e}}$ \\ a Department of Infectious Diseases \& Immunology, Faculty of Veterinary Medicine, Utrecht University, The Netherlands \\ ${ }^{\mathrm{b}}$ Veterinary Clinic Tweestromenland, Wijchen, The Netherlands \\ ' Centre for Research and Innovation in Medical Education, University Medical Center, Groningen, The Netherlands \\ d Julius Centre for Health Sciences and Primary Care, University Medical Center, Utrecht, The Netherlands \\ e Central Veterinary Institute (CVI) of Wageningen UR, The Netherlands
}

\section{A R T I C L E I N F O}

\section{Article history:}

Received 3 September 2014

Received in revised form 9 July 2015

Accepted 20 August 2015

\section{Keywords:}

Prescribing behaviour

Veterinary medicine

Farm animals

Antimicrobial resistance

Antimicrobial use

Prescribing determinants

\begin{abstract}
A B S T R A C T
Little is known about attitudes of veterinarians towards antibiotic use and reduction opportunities, and their interaction with farmers herein. Therefore, a questionnaire was developed and sent out to Dutch farm animal veterinarians. The response rate was 40\%. Categorical Principal Component Analysis (CATPCA) was conducted on statements measuring attitudes towards the use of antibiotics and reduction opportunities in farm animals, the veterinary pharmacy and the interaction of veterinarians with farmers in improving animal health. This resulted in 3 underlying dimensions. Additionally, possible explanatory variables (main farm animal species working with, years of experience in practice) were added to the CATPCA to identify differences between veterinarians. Veterinarians working with different animal species were comparable in their opinions towards the necessity to reduce veterinary antibiotic use and the current policy to halve veterinary antibiotic consumption. Veterinarians working with ruminants "ruminant specialists" - and veterinarians working with several different animal species - "generalists" - reported to feel more uncertainty in acting independently from farmers' and significant others' (other advisors, colleagues) demands for antibiotics or opinions than veterinarians mainly working with intensively raised animals (pigs, poultry, veal calves) - "intensive specialists". Years of experience in practice was negatively related to feelings of uncertainty in acting independently. At the other hand, years of experience was associated with being less concerned about the possible contribution of veterinary antibiotic use to antimicrobial resistance, considering it more important to keep the right to prescribe and sell antibiotics, and being less hesitant to apply antibiotics to prevent (further dissemination of) animal diseases. Intensive specialists expected most from improving feed quality and benchmarking of antibiotic prescribing and use in reducing veterinary antibiotic use; ruminant specialists and generalists preferred improving housing and climate conditions and benchmarking. The by veterinarians perceived main reasons for farmers not to comply to veterinary advices to improve animal health were related to financial and time restrictions, although intensive specialists stressed the importance of conflicting advices from other advisors as a cause for non-compliance. The results showed that younger veterinarians might require additional support to act independently from farmers' and significant others'. Additionally, experienced veterinarians could be educated about possible risks related to veterinary overuse of antibiotics. Alternative approaches should be identified for veterinarians to preserve a decent income without pharmacy incomes. Especially in intensive farming, ways should be found to prevent contradictory advices as a barrier not to implement veterinary advices to improve animal health.
\end{abstract}

(C) 2015 Elsevier B.V. All rights reserved.
* Corresponding author at: Department of Infectious Diseases and Immunology, Faculty of Veterinary Medicine, Yalelaan 1, 3584 CL, Utrecht, the Netherlands. Tel.: +3130253 4330; Fax: +31302533199.

E-mail address: d.c.speksnijder@uu.nl (D.C. Speksnijder).

\section{Introduction}

The emerging antimicrobial resistance in bacteria is considered to be a major threat for public health. Farm animals are regarded as high antibiotic consumers with considerable levels of avoidable antibiotic use (U.S. Department of Health and Human Services. Centres for Disease Control and Prevention, 2013). Since antibiotic 
use drives resistance, there is an urgent need to reduce antibiotic use in animals to the absolute minimum that is required to safeguard animal health but still compatible with a sustainable animal production (Angulo et al., 2009; Prescott, 2008; Aarestrup et al., 2008; McEwen, 2006).

The Dutch government in 2010 imposed the livestock sectors to reduce veterinary antibiotic usage with 50\% in 2013 and $70 \%$ in 2015 compared to 2009. After an initial rapid decrease in reduction of antibiotic use in farm animals (56\% in 2013) there is a levelling in 2014 with 58\% (MARAN, 2015). A 70\% reduction will require additional fundamental changes in the behaviour of veterinarians and farmers towards the usage of antibiotics in farm animals (Speksnijder et al., 2015b). Tailored interventions directed to veterinarians to change antibiotic prescribing behaviour of veterinarians might be effective as they are key persons in reducing antibiotic use in farm animals (Prescott, 2008; Morley et al., 2005). However, only little is known about attitudes and other influences that might influence prescribing behaviour of veterinarians.

In human medicine, prescribing decisions of physicians are influenced by clinical reasoning as well as non-clinical factors which are related to personal characteristics (e.g., years in practice, extent of medical knowledge, attitudes, relationship with patients) (Akkerman et al., 2005). Knowledge of these prescribing determinants and categorization of health care providers into different target groups is extensively used for the purpose of sustainable implementation of tailored antibiotic stewardship programs and interventions (Hulscher et al., 2010a,b; Kumar et al., 2003; Walker et al., 2001; Vander Stichele et al., 1996; Simpson et al., 2007).

Earlier qualitative research amongst Dutch farm animal veterinarians identified a broad variety of opinions regarding veterinary antibiotic use and ways to promote prudent use as well as determinants that influenced their prescribing behaviour (Speksnijder et al., 2015a). Further exploration of attitudes of farm animal veterinarians and their interaction with farmers in promoting animal health and subsequent categorization of farm animal veterinarians in different groups might support targeting interventions to promote prudent use of antibiotics more precisely. The purpose of this study was to explore differences in attitudes towards the use of antibiotics and reduction opportunities in farm animals and the interaction of veterinarians with farmers in improving animal health and reducing antibiotic use between categories of veterinarians.

\section{Materials and methods}

\subsection{Instrument}

Based on our earlier qualitative research (Speksnijder et al., 2015a) a questionnaire was designed. Questions consisted of general descriptives, 5 -point Likert scale statements ( $1=$ completely disagree; 2 =disagree; 3 = neutral; 4 = agree; 5 = completely agree), ranking questions (ranking of items on importance) and open questions assessing attitudes, knowledge and self-reported behaviour of veterinarians regarding antibiotic use and reduction opportunities in farm animals, their interactions with significant others like other advisors and colleagues and their perceived role in antibiotic reduction. The design and content of the questionnaire was discussed in an expert meeting consisting of veterinary and medical experts. The questionnaire was subsequently piloted amongst veterinarians working at the Faculty of Veterinary Medicine, Utrecht University, The Netherlands (Rattray and Jones, 2007). The questionnaire was made online available through Surveymonkey (SurveyMonkey.com, LLC, Palo Alto, California, USA).

\subsection{Questionnaire distribution}

In April 2012, an invitation to participate in an online survey was sent out to all practicing farm animal veterinarians in the Netherlands by email. Veterinarians working at least 1 day a week with farm animals were invited to participate. In total, 1770 email addresses of registered farm animal veterinarians were obtained from the Royal Dutch Veterinary Association (KNMvD). This list however appeared to be contaminated with double email addresses (private as well as company email addresses). It was not possible to reduce the number of email addresses without risking missing practising veterinarians. The exact population size of practising farm animal veterinarians in the Netherlands is not exactly known and was estimated based on the species specific registers of veterinarians which consisted of around 1100 practitioners in early 2013. After 2 and 7 weeks, reminders were automatically sent to nonresponders. This survey was also advertised in the monthly digital newsletter of the KNMvD. Responses were collected anonymously unless participants choose to leave contact details. $A € 20$ voucher for participation was provided after completion of the questionnaire.

\subsection{Data analysis}

Data were analysed using Microsoft Excel and SPSS statistics version 22 (IBM Corp.). Comparisons between categories of veterinarians were performed with the appropriate tests and post hoc analyses for the different types of data (nominal, ordinal, continuous). Continuous data (years in practice, estimated achievable reduction) were visually checked for normality.

Respondents were asked how their working time was attributed to the different animal species (1-20\%; $21-40 \% ; 41-60 \% ; 61-80 \%$; $81-100 \%$ ). Respondents working $>60 \%$ with animal species belonging to either intensively raised farm animals (poultry, swine, veal calves) or ruminants (cattle and small ruminants; not veal calves) were classified as respectively intensive specialists and ruminant specialists. Veterinarians working between 0 and $60 \%$ with animals from the different sectors (intensive, ruminant, horses and pets) were classified as generalists.

Factor analysis was performed to reduce the attitudinal variables to a number of uncorrelated principal components (dimensions) that represent the data and could further be analysed to find differences in attitudes between veterinarians and possible explanatory variables (Linting and van der Kooij, 2012). As the data in our study consisted of nominal, continuous and ordinal variables, nonlinear rather than linear analysis was chosen to analyse the data. Categorical Principal Component Analysis (CATPCA) can manage possibly nonlinearly related variables with different types of measurement level and is particularly useful to analyse Likert-type variables. CATPCA converts categorical variables to quantitative variables using optimal quantification and reduces the dataset to a smaller number of dimensions (Linting and van der Kooij, 2012; Linting et al., 2007). Component loadings are correlations between the variables and the dimensions and can graphically be represented as vectors in a biplot (two dimensional graphical display) (Linting et al., 2007). In total, 31 Likert scale statements (1: completely do not agree-5: completely agree) were treated as ordinal data and selected for CATPCA analysis. Additionally, 3 supplementary explanatory variables were added to the CATPCA; type of veterinarian (multiple nominal data), years of experience (numeric) and being a practice owner (nominal). For missing values, the default Passive CATPCA option of imputing the modal category after quantification was chosen. Scree plot analysis indicated that a 3-dimension solution was most suitable for analysis of this dataset. All variables with a total VAF of 0.25 or lower were excluded for the final analysis. The CATPCA procedure 
Table 1

Working time attributable to different animal species (proportion of respondents).

\begin{tabular}{lcrrrr}
\hline \multirow{5}{*}{ Animal species } & \multicolumn{7}{l}{ Percentage of working time } & & \\
\cline { 2 - 6 } & $1-20 \%$ & $21-40 \%$ & $41-60 \%$ & $61-80 \%$ & $81-100 \%$ \\
\hline Poultry & $35.7 \%$ & $1.6 \%$ & $0.2 \%$ & $0.5 \%$ & $1.6 \%$ \\
Swine & $38.0 \%$ & $8.2 \%$ & $3.2 \%$ & $3.0 \%$ & $6.9 \%$ \\
Cattle & $13.3 \%$ & $13.3 \%$ & $19.0 \%$ & $20.8 \%$ & $23.6 \%$ \\
Veal Calves & $37.5 \%$ & $2.5 \%$ & $0.7 \%$ & $1.6 \%$ & $2.5 \%$
\end{tabular}

was repeated until no variables with a total VAF $<0.25$ remained. Component loadings of 0.40 or higher were regarded as sufficient to calculate object scores for each dimension and were saved for further analysis (Linting and van der Kooij, 2012).

In a separate question, respondents were asked to estimate the, in their opinion, reasonably achievable reduction in veterinary antibiotic consumption (percentage) in 2015 compared to 2009 for the animal species they were working with for at least $20 \%$ of their time. This individually reported reduction estimate per animal species was divided by the mean reduction estimates per animal species to calculate the relative estimated reduction of a respondent compared to peers as a percentage (100\% being the average estimated reduction; less than $100 \%$ means being less optimistic than peers in the achievable reduction in veterinary antibiotic consumption; above $100 \%$ is more optimistic than peers). The mean scores per respondent over the different animal species were then averaged into one estimation of relative reasonably achievable reduction per respondent in comparison with peers. Parametric tests ( $t$-test, ANOVA, linear and logistic regression analysis) were used as well as non-parametric tests for proportions or ordinal data (Pearson Chi Square and Kruskal Wallis $H$-test) to test for differences and associations between variables. The answers to the open question regarding reasons why veterinary advices are not implemented were analysed iteratively using qualitative techniques.

\section{Results}

\subsection{General descriptives}

We received 437 questionnaires of which 377 were complete (response rate of $40 \%$ (34\% complete) based on the estimated number of registered veterinarians working in farm animals). The respondents were on average 15.8 (range 1-41) years in practice and $90.2 \%$ of the respondents had received their veterinary training at Utrecht University, the Netherlands. Of the respondents, $62.9 \%$ were (co) owner of a practice while the others were working on payroll. Practice owners had on average 20.6 years of experience in practice (95\%CI 19.6-21.7) and no-owners had on average 7.3 years of experience $(95 \% \mathrm{CI} 6.1-8.5$; $t$-test $p=0.000)$. The percentages of respondents $(n=437)$ reporting to work with the different farm animal species and the mean percentage of working time devoted to the different animal species are shown in Table 1, indicating for example that the majority (61\%) of the intensive specialists are mainly working with pigs.

The intensive specialists had significantly longer experience than ruminant specialists but not than generalists (ANOVA; $F=4.279 ; p=0.015$ ). Intensive specialists were significantly more often practice owner instead of working on payroll compared with the other two categories (Table 2). Besides working with farm animals, veterinarians classified as generalists attributed significantly more working time to pets (Kruskal Wallis $\mathrm{H}$ test $\chi^{2}(2)=43.585, p=0.000$ ) and horses (Kruskal Wallis $H$-test $\left.\chi^{2}(2)=81.898, p=0.000\right)$ compared to the other two categories, justifying their classification as generalists.

The 3-dimensional CATPCA solution with 18 variables explained $42.4 \%$ of the variance of the scores provided by the respondents
( 7.63 as the sum of Eigenvalues from the three dimensions divided by 18 variables). The component loadings for the 3 dimensions solution are shown in Table 3. The plots of the component loadings with the centroid coordinates of the multiple supplementary categories are shown in Figs. 1 and 2. Based on the grouping of different variables that have high value loadings on the different dimensions, three latent variables (dimensions) can be described:

- Dimension 1 is related to feelings of uncertainty to act independently from significant others' influences in antibiotic prescribing and improving animal health.

- Dimension 2 is related to being supportive of reduction of veterinary antibiotic consumption to preserve public health and less obvious fear for detrimental effects on animal health.

- Dimension 3 is related to having a lower threshold to apply antibiotics to animals and a strong believe that the veterinary pharmacy should be preserved to remain a good income.

Only for dimension 1 there was a significant difference in mean object scores between veterinarians working with different animal species. Intensive specialist (mean score -0.455 ) scored significantly lower on dimension 1 (ANOVA; $F=8.388$; Bonferoni post hoc $p=0.000)$ than ruminant specialists $(0.017)$ and generalists (0.133). For dimensions 2 and 3, no significant differences were found between veterinarians working with different animal species ( $F=2.687 ; p=0.69$ and $F=.398 ; p=0.672$ respectively). Years of experience was negatively related to dimension 1 (Linear regression analysis $B=-0.026 ; F=25.150, p=0.000$ ), not related to dimension $2(F=0.000 ; p=0.989)$ and positively related to dimension $3(B=0.021 ; F=16.909, p=0.000)$. The CATPCA analysis also indicated that years of experience was negatively associated with the believe that the veterinary contribution to antimicrobial resistance was worrisome (Fig. 1).

\subsection{Perceived achievable reduction of antibiotic consumption}

Over the major farm animal species (pigs, poultry, dairy and veal calves), the respondents estimated the highest reasonably achievable reduction (2015 compared to 2009 ) in pigs, $52.6 \%$ (95\%CI $48.8-56.3 \%$ ), followed by $39.3 \%$ (95\%CI $33.8-44.7 \%$ ) in veal calves, $35.0 \%(95 \% \mathrm{CI} 25.8-44.2 \%)$ in poultry, and the lowest in cattle with $32.8 \%$ (95\%CI 30.8-34.7\%). Years of experience was not significantly related to the relative reasonably achievable reduction in veterinary antibiotic consumption, although a trend was visible that increasing years of experience was related with a less optimistic view on the relative achievable reduction (Linear regression analysis $B=-0.445 ; F=3.085, p=0.080$ ).

\subsection{Pressure to prescribe}

The majority of respondents reported to feel pressure from clients to prescribe while they were not supporting this less than once every half a year (Table 5). However, a quarter of the intensive specialists reported to feel this pressure at least once every two months. Ordinal regression analysis with type veterinarian and years of experience revealed that an increase in experience (expressed in years) was associated with a decrease in frequency of felt pressure to prescribe $(p=0.002)$ with an odds ratio of 0.97 (95\%CI 0.95-0.99). Intensive specialist felt significantly more often forced to prescribe compared with generalist and a tendency was visible that they also more frequently felt this pressure compared with ruminant specialists $(p=0.56)$. 
Table 2

Distribution of respondents over the different categories of veterinarians and their characteristics.

\begin{tabular}{|c|c|c|c|}
\hline Veterinarian category & Number of respondents (\%) & Percentage practice owner & Mean years of experience; $95 \% \mathrm{CI}(\mathrm{N})$ \\
\hline Intensive specialist & $70(16.0 \%)$ & $82.8 \%{ }^{\mathrm{a}}$ & $18.0 ; 15.92-20.02(64)^{c}$ \\
\hline Ruminant specialist & $195(44.6 \%)$ & $53.9 \%$ b & $14.2 ; 12.54-15.80(170)^{d}$ \\
\hline Generalist & $172(39.4 \%)$ & $64.3 \%^{\mathrm{b}}$ & $16.7 ; 15.05-18.34(143)$ \\
\hline Total & $437(100 \%)$ & $62.90 \%$ & $15.8 ; 14.75-16.80(377)$ \\
\hline
\end{tabular}

${ }^{\mathrm{a}, \mathrm{b}}$ Sign differences between the groups; Pearson Chi Square $\chi^{2}(2)=16.679, p=0.000$

$c, d$ Significant difference between the two groups (ANOVA; $F=4.279, p=0.015$ ).

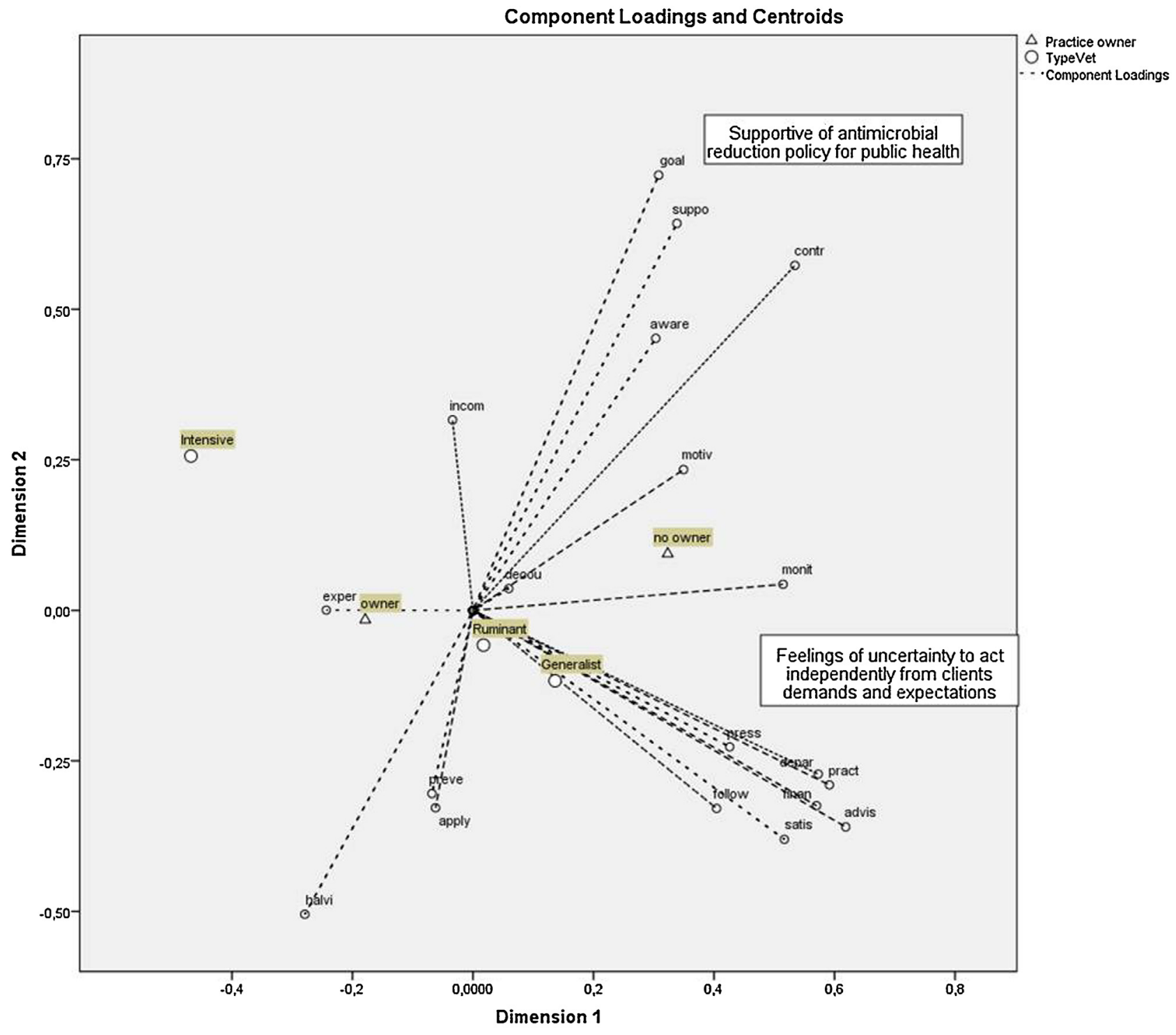

Variable Principal Normalization.

Fig.1. Biplot of component loadings for dimensions 1 and 2 for the active variables and multiple nominal category points.

\subsection{Solutions for high veterinary antibiotic use}

Respondents were asked in a single choice question which measure would in their opinion contribute the most to reduction of veterinary antibiotic consumption. Intensive specialists expected much from improving feed quality and benchmarking of antibiotic use and prescribing, while ruminant specialists and generalists expected much from improvements in housing and climate and benchmarking (Table 4).

\subsection{Perceived reasons for farmers not to implement veterinary advices}

Several reasons were ranked (5-point Likert scales) by respondents why farmers are thought to not comply with veterinary advices that would improve animal health (Table 6). They were mainly related to the financial and labour investments associated with complying with the veterinary advices and conflicting advices of other advisors. The latter was mentioned especially by intensive 
Table 3

Component Loadings of 3 dimensional CATPCA analysis.

\begin{tabular}{|c|c|c|c|c|c|}
\hline \multirow[t]{2}{*}{ Abbreviation } & \multirow[t]{2}{*}{ Variable } & \multicolumn{3}{|c|}{ Dimension } & \multirow[b]{2}{*}{ Sum } \\
\hline & & 1 & 2 & 3 & \\
\hline Contr & $\begin{array}{l}\text { The possible contribution of veterinary antibiotic use to } \\
\text { development of resistance in humans is worrisome }\end{array}$ & 0.534 & 0.573 & - & - \\
\hline Suppo & $\begin{array}{l}\text { I support the policy to halve veterinary antibiotic consumption } \\
\text { by } 2015 \text { compared to } 2013\end{array}$ & - & 0.643 & - & - \\
\hline Motiv & $\begin{array}{l}\text { An important motive for me to take up reduction of antibiotic } \\
\text { use is to conserve the right to both prescribe and sell } \\
\text { veterinary drugs }\end{array}$ & - & - & 0.647 & - \\
\hline Goal & $\begin{array}{l}\text { It is my goal to reduce antibiotic use in my practice as far as } \\
\text { possible }\end{array}$ & - & 0.723 & - & - \\
\hline Halvi & $\begin{array}{l}\text { Halving veterinary antibiotic use will be at the cost of animal } \\
\text { health and welfare }\end{array}$ & - & -0.505 & - & - \\
\hline Aware & $\begin{array}{l}\text { I have become more aware of the necessity to apply antibiotics } \\
\text { restrictively last years }\end{array}$ & - & 0.452 & - & - \\
\hline Preve & $\begin{array}{l}\text { Confronted with sick animals with a probable bacterial } \\
\text { infection, I prefer to immediately apply antibiotics to prevent } \\
\text { further exacerbation of the disease }\end{array}$ & - & - & 0.445 & - \\
\hline \multirow[t]{7}{*}{ Apply } & $\begin{array}{l}\text { I do not have difficulties with applying antibiotics when I think } \\
\text { I can prevent animal diseases }\end{array}$ & - & - & 0.477 & - \\
\hline & $\begin{array}{l}\text { I feel a need for clear criteria to help me decide whether I } \\
\text { should continue or finish an antibiotic treatment }\end{array}$ & - & - & - & - \\
\hline & Farmers regularly fail to apply antibiotics correctly & - & - & - & - \\
\hline & $\begin{array}{l}\text { Farmers regularly have difficulties in complying to their } \\
\text { treatment protocols when treating animals }\end{array}$ & - & - & - & - \\
\hline & $\begin{array}{l}\text { In our practice, we consciously take time to exchange } \\
\text { knowledge and experience between colleagues }\end{array}$ & - & - & - & - \\
\hline & $\begin{array}{l}\text { I feel a need for more knowledge exchange between my } \\
\text { colleagues and myself }\end{array}$ & - & - & - & - \\
\hline & $\begin{array}{l}\text { I would like my advising role for farmers to become more } \\
\text { prominent in my daily activities }\end{array}$ & - & - & - & - \\
\hline Advis & $\begin{array}{l}\text { I consider it difficult to obtain a position as advisor amongst all } \\
\text { other advisors that advice a farmer }\end{array}$ & 0.619 & - & - & - \\
\hline \multirow[t]{2}{*}{ Pract } & $\begin{array}{l}\text { I consider it difficult to give practical advices to a farmer that } \\
\text { contribute to improvements of animal health }\end{array}$ & 0.591 & - & - & - \\
\hline & $\begin{array}{l}\text { In my approach of farmers, I consciously adapt my } \\
\text { communication style to the type of farmer I have to deal with }\end{array}$ & - & - & - & - \\
\hline \multirow[t]{3}{*}{ Follow } & $\begin{array}{l}\text { When I expect a farmer not to follow a certain advice, I will not } \\
\text { give that advice }\end{array}$ & 0.404 & - & - & - \\
\hline & $\begin{array}{l}\text { I regularly am confronted with sick animals that likely could } \\
\text { have been prevented when a farmer had complied to my } \\
\text { advice }\end{array}$ & - & - & - & - \\
\hline & $\begin{array}{l}\text { I often feel uncomfortable to charge the full amount of time } \\
\text { that I spend on advising a farmer }\end{array}$ & - & - & - & - \\
\hline \multirow[t]{2}{*}{ Monit } & $\begin{array}{l}\text { When I could monitor animal health on a farm more } \\
\text { frequently, antibiotic use on that farm can be lowered further }\end{array}$ & 0.515 & - & - & - \\
\hline & $\begin{array}{l}\text { I am in favour of compulsory post graduate education for } \\
\text { veterinarians }\end{array}$ & - & - & - & - \\
\hline Depar & $\begin{array}{l}\text { I consider it difficult to depart from routines that farmers are } \\
\text { accustomed to }\end{array}$ & 0.573 & - & - & - \\
\hline \multirow[t]{2}{*}{ Press } & $\begin{array}{l}\text { I once in a while feel pressure from colleagues to perform } \\
\text { activities which I in fact do not support, such as prescribing } \\
\text { antibiotics }\end{array}$ & 0.426 & - & - & - \\
\hline & Appreciation of farmers for my work is very important for me & - & - & - & - \\
\hline Finan & $\begin{array}{l}\text { Because of my financial dependency on a farmer, I do not } \\
\text { always dare to be critical about the demeanour of the farmer }\end{array}$ & 0.570 & - & - & - \\
\hline \multirow[t]{2}{*}{ Satis } & $\begin{array}{l}\text { I need to keep my clients satisfied, therefore I cannot refuse an } \\
\text { explicit demand for antibiotics }\end{array}$ & 0.517 & - & - & - \\
\hline & $\begin{array}{l}\text { I regularly am confronted with situations in which } \\
\text { non-veterinary advisors advice farmers about antibiotic } \\
\text { treatments }\end{array}$ & - & - & - & - \\
\hline Decou & $\begin{array}{l}\text { The decoupling of prescribing and dispensing antibiotics by } \\
\text { veterinarians should be effectuated }\end{array}$ & - & - & -0.570 & - \\
\hline \multirow[t]{2}{*}{ Incom } & $\begin{array}{l}\text { I am able to earn a decent income without incomes from the } \\
\text { pharmacy in } 5 \text { years from now }\end{array}$ & - & - & -0.487 & - \\
\hline & $\begin{array}{l}\text { Without pharmacy incomes, my hourly tariffs must } \\
\text { substantially increase to guarantee a same level of income }\end{array}$ & - & - & - & - \\
\hline \multirow[t]{4}{*}{ Exper } & Years of experience ${ }^{a}$ & - & - & - & - \\
\hline & Total (Eigenvalue) & 3.063 & 2.777 & 1.788 & 7.628 \\
\hline & Cronbach's $\alpha$ & 0.713 & 0.678 & 0.467 & 0.920 \\
\hline & $\operatorname{VAF}(\%)$ & 17.0 & 15.4 & 9.9 & 42.4 \\
\hline
\end{tabular}

Variables in italics were not selected for final analysis because the VAF was $<0.25$

a Supplementary variable. 


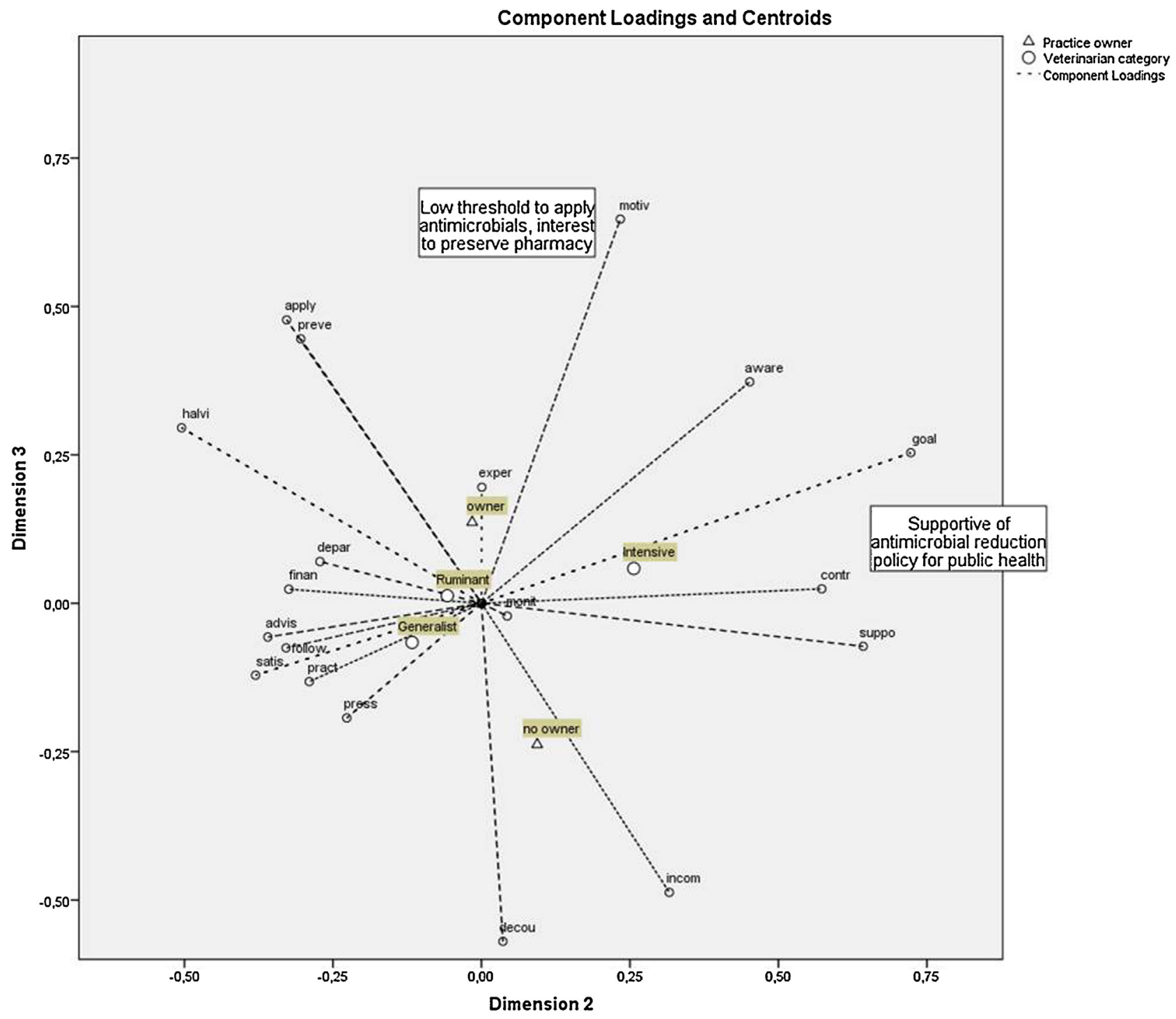

Variable Principal Normalization.

Fig. 2. Biplot of component loadings for dimensions 2 and 3 for the active variables and multiple nominal category points.

Table 4

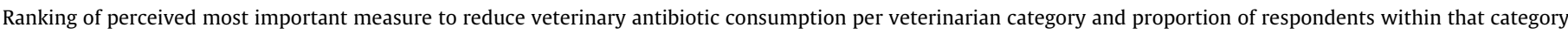
choosing this measure as most important measure.

\begin{tabular}{|c|c|c|c|c|c|c|}
\hline \multirow[t]{2}{*}{ Proposed measure } & \multicolumn{2}{|c|}{ Intensive } & \multicolumn{2}{|c|}{ Ruminant } & \multicolumn{2}{|c|}{ Generalist } \\
\hline & $\%$ & Ranking & $\%$ & Ranking & $\%$ & Ranking \\
\hline Uncoupling the prescribing and dispensing of antibiotics by veterinarians & 0.0 & - & 0.6 & 11 & 1.9 & 9 \\
\hline Introduction of an antibiotic tax & 15.2 & 3 & 10.1 & 4 & 12.1 & 3 \\
\hline Benchmarking of antibiotic use, including sanctioning of high users & 16.7 & 2 & 18.4 & 2 & 25.5 & 1 \\
\hline Improving biosecurity on farms & 6.1 & 5 & 4.5 & 9 & 0.7 & 5 \\
\hline Improving the quality of animal feed & 37.9 & $1^{\mathrm{a}}$ & 7.3 & $6^{\mathrm{b}}$ & 0.7 & $5^{\mathrm{b}}$ \\
\hline Improvements in housing and climate & 4.5 & $7^{\mathrm{a}}$ & 25.7 & $1^{\mathrm{b}}$ & 22.9 & $2^{\mathrm{b}}$ \\
\hline Increasing efforts to eradicate infectious diseases & 6.1 & 5 & 10.6 & 3 & 5.7 & 7 \\
\hline Restricting treatments only for diseased animals & 4.5 & 7 & 0.5 & 8 & 10.2 & 4 \\
\hline Increasing the use of supportive treatments (like NSAIDs) & 0.0 & - & 2.2 & 10 & 0.0 & - \\
\hline Increasing education for farmers on prevention of infectious diseases & $0.0^{\mathrm{a}}$ & - & $8.9^{\mathrm{b}}$ & 5 & $4.5^{\mathrm{a}, \mathrm{b}}$ & 8 \\
\hline Increasing post graduate education for veterinarians on feed and climate & 0.0 & - & 0.6 & 11 & 0.0 & - \\
\hline Improving communicative skills of veterinarians & 1.5 & 8 & 0.6 & 11 & 1.3 & 11 \\
\hline Others & 7.6 & 4 & 5.6 & 7 & 1.9 & 9 \\
\hline
\end{tabular}

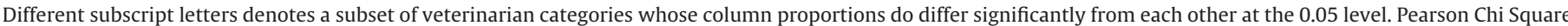
$\chi^{2}(24)=85.669, p=0.000$. 
Table 5

Proportion of different answers given to the question "I feel forced to prescribe antibiotics while I do not really support this".

\begin{tabular}{|c|c|c|c|c|c|}
\hline & Never & At least once a year & At least once every 6 months & At least once every 2 months & At least once every month \\
\hline Intensive $\mathrm{a}^{\mathrm{a}}$ & $26.6 \%$ & $21.9 \%$ & $25.0 \%$ & $10.9 \%$ & $15.6 \%$ \\
\hline Ruminants & $32.4 \%$ & $31.2 \%$ & $26.5 \%$ & $8.2 \%$ & $1.8 \%$ \\
\hline Generalists $^{\mathrm{b}}$ & $38.2 \%$ & $24.3 \%$ & $22.9 \%$ & $12.5 \%$ & $2.1 \%$ \\
\hline Total & $33.6 \%$ & $27.0 \%$ & $24.9 \%$ & $10.3 \%$ & $4.2 \%$ \\
\hline
\end{tabular}

a,b Significant difference between a and b; Kruskal Wallis $H$-test $\chi^{2}(2)=6.778, p=0.034$.

Table 6

Proportion of respondents scoring the following perceived reasons of farmers not to implement veterinary advices as "important" and “very important".

\begin{tabular}{|c|c|c|c|c|}
\hline Perceived reasons & Intensive & Ruminant & Generalist & Total \\
\hline Other advisors give conflicting advices & $79.7 \%$ & $54.4 \%$ b & $66.0 \%$ & $63.1 \%$ \\
\hline $\begin{array}{l}\text { Farmers regard implementation of veterinary advices too } \\
\text { expensive }\end{array}$ & $56.3 \%$ c & $65.9 \%$ & $78.5 \%$ d & $69.0 \%$ \\
\hline $\begin{array}{l}\text { Farmers regard implementation of veterinary advices too time } \\
\text { consuming }\end{array}$ & $75.0 \%$ & $74.1 \%$ & $81.9 \%$ & $77.2 \%$ \\
\hline $\begin{array}{l}\text { Farmers do not believe that implementing veterinary advices } \\
\text { will have better outcomes }\end{array}$ & $20.3 \%$ & $31.6 \%$ & $33.3 \%$ & $30.3 \%$ \\
\hline $\begin{array}{l}\text { Farmers regard implementation of veterinary advices in } \\
\text { practice too difficult }\end{array}$ & $49.2 \%$ & $51.5 \%$ & $52.4 \%$ & $51.5 \%$ \\
\hline
\end{tabular}

a,b Significant difference between groups; Kruskal Wallis H-test $\chi^{2}(2)=15,529, p=0.000$.

c,d Significant difference between groups; Kruskal Wallis H-test $\chi^{2}(2)=8987, p=0.011$.

specialists to be important. Analysis of entered free texts indicated that several respondents believed that inveterate habits are not easy to change for farmers; especially when farmers do not see the need to change behaviour. Other respondents also mentioned the difficulties related to predicting the (cost) effectiveness of specific measures in the context of a specific farm. Then it was perceived as difficult to convince a farmer of the necessity of implementing specific measures.

\section{Discussion}

This study offers insights in different attitudes of different categories of farm animal veterinarians in the Netherlands towards antibiotic use and antimicrobial resistance in farm animals and their interaction with farmers herein.

\subsection{Strengths $\mathcal{E}$ limitations of the study}

The response rate of $34 \%$ based on completed questionnaires ( $40 \%$ returned) is relatively low, however reasonable when compared with others (Gunn et al., 2008; Dean et al., 2011; Cattaneo et al., 2009). In this study there appeared no bias in respondents for distribution of veterinarians over the different farm animal species according to the species specific registers, indicating that a good sample of the whole population of farm animal veterinarians was taken. The mean experience in practice in this study was 15.8 years. Given the mean age of graduation of Dutch veterinarians at 28 years (Jaarsma et al., 2008), the mean age of the respondents in this study should be around 44 years of age which is comparable to the reported mean age of practising veterinarians in the Netherlands of 45 years (KNMvD, personal communication).

This study was performed in the Dutch context where in the recent years policies and public opinion regarding veterinary antibiotic use have changed drastically (Speksnijder et al., 2015b). These developments might have already changed some of the attitudes of farm animal veterinarians. Nevertheless, the gatekeeper role of veterinarians for antibiotic use and the encountered conflicts with demanding farmers is not restricted to the Dutch situation and these findings might therefore be relevant for comparable animal production systems where increasing attention exists to promote prudent use of antibiotics.

\subsection{Comparison with existing literature}

In our study we found that veterinarians with fewer years in practice experienced the most uncertainty to act as an independent advisor and the most frequent explicit pressure from their clients to prescribe antibiotics while they were not supporting this. It has to be said that in general the latter was not often felt in this study as more than half of the respondents reported to only feel this pressure twice a year or less. Coyne et al. (2014) in their study on pig veterinarians found that perceived pressure from clients can be a driver to prescribe antibiotics, but also mentioned the mutual relationship between veterinarian and farmer to be influential in prescribing behaviour. Studies on doctor-patient interactions show that seniority can be associated with being more 'patient-centred'. This is characterized by a more flexible style of interaction in which physicians are better able to identify the extent to which patients want to be involved in decision making, to adapt to the needs of their patients and to refuse patients' demands (Krupat et al., 2000; Walter et al., 2012). This might be also true for well-established long lasting veterinarian-farmer relationships in which more experienced veterinarians are better able to elicit farmers' true demands and have a more flexible style of interaction to act as an independent and sometimes critical advisor and better able to resist pressure from clients. For younger veterinarians who like to build a long lasting mutual relationship with a farmer as a client, it might feel uncomfortable to be too paternalistic towards a farmer or to refuse strong demands. Another explanation for this finding might be that older veterinarians are less reluctant in antibiotic prescribing anyway and pressure from clients is not required or the pressure is perceived less by the older veterinarians (Akkerman et al., 2005). In our study we found that increasing experience is associated with being less concerned about a possible veterinary contribution to antimicrobial resistance and also being less concerned to prescribe antibiotics to prevent animal diseases. Cattaneo et al. (2009) also found a negative relationship between years of practical experience and knowledge about consequences of antimicrobial resistance in bovine veterinarians. This might probably lower the barrier of older veterinarians to irrationally prescribe antibiotics when clients demand for it and probably also clients' demand is less easily interpreted as pressure.

More experienced veterinarians in our study had a more pronounced opinion on the importance of keeping the right to 
prescribe and sell antimicrobials. One explanation for this observation might be that this group contains the highest proportion of practice owners who are personally responsible to run a profitable practice and see fewer opportunities for alternative incomes when the veterinary pharmacy would be removed from their practice. This might also explain the observation that younger vets have more optimistic views on the reasonably achievable reduction in antibiotic consumption. Another explanation for this might be that younger veterinarians are during their training already more exposed to the success of preventive veterinary medicine and therefore have more optimistic views on the reduction possibilities.

Intensive veterinarians felt the least insecurity to act as an independent advisor. This might be related to the longer experience of intensive specialists, but also to the fact that advising instead of clinical work has become more and more a core business in the intensive farm animal sectors compared to other (farm) animal sectors.

\subsection{Proposed measures to reduce veterinary antibiotic use}

Where a large proportion of intensive specialists (the majority being pig veterinarians) believed most in improving quality of animal feed and benchmarking as important measures for reduction of antibiotic use, ruminant specialists and generalists preferred improvements in housing and climate next to benchmarking, indicating that probably different measures are needed in different animal sectors for reduction of antibiotic use. Coyne et al. (2014) found that pig veterinarians and pig farmers in the UK mentioned poor housing conditions as a very important hurdle in reducing antibiotic use, however this was not really confirmed by our findings in this study. Probably, Dutch farmers with intensively kept animals have already improved their housing conditions in the last years to such an extent that veterinarians see less need for improvement compared to other measures like improving feed quality. Postma et al. (2015) confirmed the finding that improving feed quality in pig production was a highly ranked measure amongst important stakeholders in the pig industry. Improvements in housing and climate were regarded as important measures by ruminant specialists in our study which is in accordance with findings of other authors who stressed the importance of a balanced housing system for dairy cows to prevent diseases (LeBlanc et al., 2006; Vaarst et al., 2006).

Interestingly, benchmarking was ranked highly amongst all respondents in our study as an important measure for reduction of antibiotic use, in contrast to for example the study of Postma et al. (2015) were it was ranked quite low; Dutch stakeholders were not involved in that study. This might probably be explained by the fact that mandatory benchmarking of prescription and use of veterinary antibiotics was already introduced at the time of questionnaire distribution (Speksnijder et al., 2015b) and veterinarians probably saw the first positive results from this in the field. Benchmarking in fact appeared to be effective in the Netherlands to reduce antibiotic use in farm animals (Speksnijder et al., 2015b).

\subsection{Veterinary advices and farmers' compliance}

Several authors have stressed the importance of preventive strategies to reduce diseases and antibiotic use in farm animals, the important role of veterinarians as partners for farmers herein and the importance of a comprehensive animal health planning strategy with farmers' compliance on individual farms (Brennan and Christley, 2013; Friedman et al., 2007; Cattaneo et al., 2009; LeBlanc et al., 2006). Financial and practical (time) restrictions or the perceived insufficient return on investment as found in our study, are known important reasons for farmers not to implement preventive measures (Derks et al., 2013; Friedman et al., 2007; Laanen et al., 2014; Wierup, 2000; Leach, 2008; Coyne et al., 2014), which is supported by our findings. However, several authors indicated that receiving more explanation about the importance of preventive measures by the herd veterinarian and showing the cost effectiveness of investments in animal health might help to increase interest of farmers to implement preventive measures (Brennan and Christley, 2012; Lam et al., 2011; Kristensen and Jakobsen. 2011; Laanen et al., 2014). The training of veterinarians as confident and independent advisors might help in resisting demands for antibiotics by farmers or in dealing with conflicting advices of non-veterinary advisors. By eliciting the true expectations and worries of farmers by improved communication techniques, it might be possible to find alternative solutions for the problem than just meeting the demand for antibiotics. Similar techniques have successfully been used in human healthcare to help medical doctors deal with demands for antibiotics by patients (Cals et al., 2009; Little et al., 2013). To counter conflicting advices of other advisors, it might be useful to include all involved parties (farmers, veterinarians, nutritionists and others) in the process of setting up and implementing animal health promoting activities Tremetsberger and Winckler, (2015).

\subsection{Implications for future research and clinical practice}

Younger veterinarians who have found to feel more uncertain to act independently might require additional support (training, guidelines) to act independently of farmers' and significant others' (other influential advisors for farmers, colleagues) wishes and demands. Younger professionals might be more receptive to new standards of care and these protocols might give them extra support in dealing with unwilling farmers (Choudhry et al., 2005; Walter et al., 2012). Additionally, efforts could be directed to more experienced veterinarians to educate them about possible risks related to overuse of veterinary antibiotics (Simpson et al., 2007) and feasible ways should be found and communicated to profitably change from reactive and curative veterinary practice which relies much on pharmacy incomes, towards proactive and preventive activities with less dependency on the veterinary pharmacy. The challenge for the future is that veterinarians, as independent and critical advisor, support farmers in developing a comprehensive animal health plan which is supported by all relevant advisors and subsequently support the farmer with the compliance to this plan (Speksnijder et al., 2015a; Tremetsberger and Winckler, 2015).

In conclusion: based on the questionnaire we were able to categorize the Dutch farm animal practitioners based on their attitudes regarding antibiotic use and antimicrobial resistance, and their relation towards the farmers. Following this categorization, interventions can be developed to target the different categories based on their profiles.

\section{Acknowledgement}

This study was funded by ZonMW (Netherlands Organization for Health Research and Development), project no. 205100009.

All respondents are kindly acknowledged for their participation in this study.

\section{Appendix A. Supplementary data}

Supplementary data associated with this article can be found, in the online version, at http://dx.doi.org/10.1016/j.prevetmed.2015. 08.014 . 


\section{References}

Aarestrup, F.M., Wegener, H.C., Collignon, P., 2008. Resistance in bacteria of the food chain: epidemiology and control strategies. Expert Rev. Anti Infect. Ther. 6 (October (5)), 733-750.

Akkerman, A.E., Kuyvenhoven, M.M., Van der Wouden, Johannes C., Verheij, T.J., 2005. Prescribing antibiotics for respiratory tract infections by GPs: management and prescriber characteristics. Br. J. Gen. Pract. 55, 114-118.

Angulo, F.J., Collignon, P., Powers, J.H., Chiller, T.M., Aidara-Kane, A., Aarestrup, F.M., 2009. World health organization ranking of antimicrobials according to their importance in human medicine: a critical step for developing risk management strategies for the use of antimicrobials in food production animals. Clin. Infect. Dis. 49, 132-141.

Brennan, M.L., Christley, R.M., 2013. Cattle producers' perceptions of biosecurity BMC Vet. Res. 9, 71

Brennan, M.L., Christley, R.M., 2012. Biosecurity on cattle farms: a study in north-west England. PLoS One 7, e28139.

Cals, J.W., Butler, C.C., Hopstaken, R.M., Hood, K., Dinant, G., 2009. Effect of point of care testing for $\mathrm{C}$ reactive protein and training in communication skills on antibiotic use in lower respiratory tract infections: cluster randomised trial. BMJ 338.

Cattaneo, A., Wilson, R., Doohan, D., LeJeune, J., 2009. Bovine veterinarians knowledge, beliefs, and practices regarding antibiotic resistance on Ohio dairy farms. J. Dairy Sci. 92, 3494-3502.

Choudhry, N.K., Fletcher, R.H., Soumerai, S.B., 2005. Systematic review: the relationship between clinical experience and quality of health care. Ann. Intern. Med. 142, 260-273.

Coyne, L.A., Pinchbeck, G.L., Williams, N.J., Smith, R.F., Dawson, S., Pearson, R.B., Latham, S.M., 2014. Understanding antimicrobial use and prescribing behaviours by pig veterinary surgeons and farmers: a qualitative study. Vet. Res. 175, 593.

Dean, W.R., McIntosh, W.A., Scott, H.M., Barling, K.S., 2011. The role of trust and moral obligation in beef cattle feed-lot veterinarians' contingent adoption of antibiotic metaphylaxis recommendations. Int. J. Soc. Agric. Food 18, 104-120.

Derks, M., van Werven, T., Hogeveen, H., Kremer, W., 2013. Veterinary herd health management programs on dairy farms in the Netherlands: use, execution, and relations to farmer characteristics. J. Dairy Sci.

Friedman, D., Kanwat, C., Headrick, M., Patterson, N., Neely, J., Smith, L., 2007. Importance of prudent antibiotic use on dairy farms in South Carolina: a pilot project on farmers' knowledge, attitudes and practices. Zoonoses Public Health $54,366-375$.

Gunn, G.J., Heffernan, C., Hall, M., McLeod, A., Hovi, M., 2008. Measuring and comparing constraints to improved biosecurity amongst GB farmers, veterinarians and the auxiliary industries. Prev. Vet. Med. 84, 310-323.

Hulscher, M., Grol, R., van der Meer, J., 2010a. Antibiotic prescribing in hospitals: a social and behavioural scientific approach. Lancet Infect. Dis. 10, 167-175.

Hulscher, M., van der Meer, J., Grol, R., 2010b. Antibiotic use: how to improve it? Int. J. Med. Microbiol. 300, 351-356.

Jaarsma, D.A., Dolmans, D.H., Scherpbier, A.J., Van Beukelen, P., 2008. Preparation for practice by veterinary school: a comparison of the perceptions of alumni from a traditional and an innovative veterinary curriculum. J. Vet. Med. Educ. 35, 431-438.

Kristensen, E., Jakobsen, E.B., 2011. Challenging the myth of the irrational dairy farmer; understanding decision-making related to herd health. New Zeal. Vet. J. 59 (1), 1-7.

Krupat, E., Rosenkranz, S.L., Yeager, C.M., Barnard, K., Putnam, S.M., Inui, T.S., 2000 The practice orientations of physicians and patients: the effect of doctor?patient congruence on satisfaction. Patient Educ Couns 39, 49-59.

Kumar, S., Little, P., Britten, N., 2003. Why do general practitioners prescribe antibiotics for sore throat? Grounded theory interview study. BMJ 326, 138.
Laanen, M., Maes, D., Hendriksen, C., Gelaude, P., De Vliegher, S., Rosseel, Y., Dewulf, J., 2014. Pig, cattle and poultry farmers with a known interest in research have comparable perspectives on disease prevention and on-farm biosecurity. Prev. Vet. Med. 115, 1-9.

Lam, T., van den Borne, B., Renes, R., Hogeveen, H., 2011. What veterinarians need to know about communication to optimise their role as advisors on udder health in dairy herds. New Zeal. Vet. J. 59, 8-15.

Leach KA, W. H. 2008. Development of a lameness control programme for dairy cattle. welfarequality.net

LeBlanc, S.J., Lissemore, K.D., Kelton, D.F., Duffield, T.F., Leslie, K.E., 2006. Major advances in disease prevention in dairy cattle. J. Dairy Sci. 89, 1267-1279.

Linting, M., Meulman, J.J., Groenen, P.J., der, K., koojj, Anita J., 2007. Nonlinear principal components analysis: introduction and application. Psychol. Methods 12,336.

Linting, M., van der Kooij, A., 2012. Nonlinear principal components analysis with CATPCA: a tutorial. J. Pers. Assess. 94, 12-25.

MARAN, 2015. MARAN 2015 Monitoring of Antimicrobial Resistance and Antibiotic Usage in Animals in The Netherlands in 2014.

McEwen, S.A., 2006. Antibiotic use in animal agriculture: what have we learned and where are we going? Anim. Biotechnol. 17, 239-250

Morley, P.S., Apley, M.D., Besser, T.E., Burney, D.P., Fedorka-Cray, P.J., Papich, M.G., Traub-Dargatz, J.L., Weese, J.S., 2005. Antimicrobial drug use in veterinary medicine. J. Vet. Intern. Med. 19, 617-629.

Postma, M., Stärk, K.D., Sjölund, M., Backhans, A., Beilage, E.G., Lösken, S., Belloc, C., Collineau, L., Iten, D., Visschers, V., 2015. Alternatives to the use of antimicrobial agents in pig production: a multi-country expert-ranking of perceived effectiveness, feasibility and return on investment. Prev. Vet. Med. $118,457-466$.

Prescott, J.F., 2008. Antimicrobial use in food and companion animals. Anim. Health Res. Rev. 9, 127-133.

Rattray, J., Jones, M.C., 2007. Essential elements of questionnaire design and development. J. Clin. Nurs, 16, 234-243.

Simpson, S.A., Wood, F., Butler, C.C., 2007. General practitioners' perceptions of antimicrobial resistance: a qualitative study. J. Antimicrob. Chemother. 59, $292-296$.

Speksnijder, D., Jaarsma, A., Gugten, A., Verheij, T., Wagenaar, J., 2015. Determinants associated with veterinary antimicrobial prescribing in farm animals in the Netherlands: a qualitative study. Zoonoses Public Health 62 (s1), 79-87.

Speksnijder, D., Mevius, D., Bruschke, C., Wagenaar, J., 2015. Reduction of veterinary antimicrobial use in the Netherlands. The Dutch success model. Zoonose Public Health 62 (s1), 79-87.

Tremetsberger, L., Winckler, C., 2015. Effectiveness of animal health and welfare planning in dairy herds: a review. Anim. Welf. 24, 55-67.

U.S. Department of Health and Human Services. Centres for Disease Control and Prevention, 2013: Antibiotic resistance threats in the United States, 2013.

Vaarst, M., Bennedsgaard, T.W., Klaas, I., Nissen, T.B., Thamsborg, S.M., Østergaard, S., 2006. Development and daily management of an explicit strategy of nonuse of antimicrobial drugs in twelve danish organic dairy herds. J. Dairy Sci. 89, $1842-1853$.

Vander Stichele, R., De Potter, B., Vyncke, P., Bogaert, M., 1996. Attitude of physicians toward patient package inserts for medication information in Belgium. Patient Educ. Couns. 28, 5-13.

Walker, A.E., Grimshaw, J.M., Armstrong, E.M., 2001. Salient beliefs and intentions to prescribe antibiotics for patients with a sore throat. Br. J. Health Psychol. 6, 347-360.

Walter, A., Chew-Graham, C., Harrison, S., 2012. Negotiating refusal in primary care consultations: a qualitative study. Fam. Pract. 29, 488-496.

Wierup, M., 2000. The control of microbial diseases in animals: alternatives to the use of antibiotics. Int. J. Antimicrob. Agents 14, 315-319. 